\title{
Gas Sensors Based on Membrane Diffusion for
}

\section{Environmental Monitoring}

\author{
Tianling $\mathrm{Li}^{\mathrm{a}}$, Yonghong $\mathrm{Wu}^{\mathrm{b}}$, Jianyin Huang ${ }^{\mathrm{a}}$, Shanqing Zhang ${ }^{\mathrm{a}^{*}}$ \\ ${ }^{a}$ Centre for Clean Environment and Energy, School of Environment, Environmental Futures \\ Research Institute, Gold Coast Campus, Griffith University, QLD, 4222, Australia \\ ${ }^{b}$ State Key Laboratory of Soil and Sustainable Agriculture, Institute of Soil Science, Chinese \\ Academy of Sciences, No.71, East Beijing Rd, Nanjing 210008, PR China
}

${ }^{*}$ Corresponding Author

Prof. Shanqing Zhang, Tel: +61-7-55528155, Fax: +61-7-55528067, E-mail: s.zhang@griffith.edu.au 


\begin{abstract}
Over the last few decades, gas membrane diffusion has been applied to elaborate chemical analyses, leading to the development of a series of gas sensing techniques for environmental monitoring. This work reviews the gas sensors that incorporate the gas membrane diffusion mechanism with either electrochemical or optical transducers, and concludes the theoretical relationship between the detection signal and the mass transfer parameters across the membrane, such as membrane thickness, gas diffusion coefficient and driving force. It also envisages that, with the availability of modern electronic and computing technology, the in-situ membrane diffusion rate of a target species is proportional to its real-time concentration in the sample and can be readily measured. Such a measuring principle is promising in developing the next generation of gas sensors based on membrane diffusion to achieve real-time and continuous monitoring of important trace gases (e.g. $\mathrm{CO}_{2}, \mathrm{SO}_{2}, \mathrm{NH}_{3}$ ) in the natural environment (water, soil and air).
\end{abstract}

Keywords: Membrane separation, gas diffusion, gas sensing techniques, real-time, environmental monitoring 


\section{Introduction}

Membrane separation has been widely used in industrial applications, such as the desalination of sea water for drinking water production [1], disinfection in wastewater treatment [2], haemodialysis and artificial lungs in the medical industry [3], filtration and concentration in the food industry [4], and the recovery of materials and/or energy in environmental protection [5]. Over the past decades, advances in electronic and computing technology have inspired overwhelming development in instrumentation, computerization and automation of chemical analysis based on membrane separation, especially membrane diffusion (i.e. membrane-based sensors), to meet the increasing demand for in-situ and continuous monitoring in environmental protection and industrial production, leading to significant progress and commercialization of sensing technology.

Usually, a typical membrane-based gas sensor consists of a gas permeable membrane, a signal transducer, and an internal recognition component (Figure 1). The gas analytes diffuse through the membrane and react with the internal recognition components, producing chemical or biochemical changes that are measurable by the transducers [6]. The internal recognition reaction can be classified into two categories: chemical recognition for chemical sensors and biochemical recognition for biosensors. The chemical sensors employ an internal electrolyte solution, such as weak acid, weak base, dye, or redox couple, to chemically recognize analytes while the biosensors utilize biochemical recognition components, such as enzymes, bacteria, cells, and antibodies, to identify analytes via biochemical or biological processes.

The membrane plays a vital role in sensing analytes in the environment: firstly, the membrane introduces a selective passage for analyte molecules through the membrane and regulates the diffusion kinetics; secondly, it remains the sensing component within the sensor body and protects the transducers from possible contaminants. Therefore, membrane-based sensors can selectively recognize gas analytes and it is independent of the matrix of the sample, which is superior to other 
sensors without membrane that is greatly affected by sample matrix, such as some polymerabsorption chemiresistors and some mass gas sensors [6-8].

In general, the membrane provides a selective barrier between any two phases, such as two liquid phases, or two gas phases, or a liquid phase and a gas phase [6], and restricts the transport of various gas species in a rather specific manner [9]. The selectivity is achieved by passing one or more components of a stream through the membrane while retarding the passage of one or more other components (Figure 2a). Donor phase is represented the phase from which mass transfer occurs and acceptor phase is represented the phase that receives the permeated mass [10]. In principle, all materials that form sufficiently thin and stable films can be used as membranes, including metal, glass, ceramics and polymers as well as ordered molecular monolayers of liquids [11].

The membrane used in the membrane-based sensing device can usually be classified into three classes based on their flux density and selectivity, i.e. porous membrane, non-porous membrane and asymmetric membrane [11] (Table 1). A porous membrane is a rigid, highly voided structure with randomly distributed inter-connected pores. The selectivity by the porous membranes is mainly a function of the permeate character (e.g. the size of the permeate molecules) and membrane properties (i.e. the molecular size of the membrane polymer, pore size and pore-size distribution). Usually, highly porous membranes exhibit high levels of flux but low selective efficiency. Non-porous or dense membranes select the permeants on the basis of their mass transport due to different solubility in the membrane. This can provide high selectivity but the rate of substrate transport is usually low. Asymmetric membranes are normally used when asymmetry in the pores is required. It consists of one thin, dense selective skin (i.e. barrier layer) and one thick, porous matrix (substructure) layer. The asymmetric membranes can present a fast transfer rate of permeants but considerably increase the mechanical resistance [6]. 
Table 1 The characteristics of three general types of gas membranes.

\begin{tabular}{cccc}
\hline Types & Selectivity & Flux density & Applicability \\
\hline Porous membrane & Low & High & Most gas species \\
Non-porous membrane & High & Low & Small-molecule gas species \\
Asymmetric membrane & High & High & Gas sensing under high pressure conditions \\
\hline
\end{tabular}

Gas analytes pass through the membrane to reach the internal recognition component mainly through the diffusion of gas molecules, namely, membrane diffusion. This uses membranes (usually polymeric porous or nonporous hydrophobic membranes or asymmetric membrane) that are inert to the permeated substances to extract gas from gas phases or aqueous solutions [12]. The extraction of the gaseous species in any gas-diffusion process is limited by their rate of diffusion through the membrane, and driven by the gas molecular diffusion that results from the different chemical potential across the membrane, such as gradients in temperature, (partial) pressure, concentration and electrical potential of the analyte [13]. Usually, membrane diffusion is a fast process and can be carried out at room temperature. More importantly, irrespective of the complexity of the principles of substance determination, membrane diffusion processes can be easily incorporated in the automation of chemical sensors, flow injection analysis (FIA), capillary electrophoresis [14], gas chromatography (GC), and high-performance liquid chromatography (HPLC) [15].

In recent years, demand for continuous reliable sensors for on-line, in-situ and real-time monitoring of gaseous species in environmental and industrial processes has been continuously increasing. Such research and development have been applied in various areas [16, 17], such as the mining industry (e.g. methane detection) [18], automotive industry (e.g. detection of polluting gases CO and NO from vehicles) [19], medical industry (e.g. electronic noses simulating the human olfactory system) [20], indoor air quality (e.g. detection of toxic gases, such as benzene, toluene and methane) [21], agriculture (e.g. $\mathrm{NH}_{3}$ and $\mathrm{NO}_{2}$ ) and in environmental studies (e.g. greenhouse gas monitoring) [2224]. This review systematically focuses on introducing (i) membrane-based gas sensors and their diffusion mechanism of gas species across the membrane, (ii) chemical and biochemical recognition 
principles of the corresponding transducers, and (iii) potential research and development directions of the membrane diffusion in real-time gas sensing in in-situ environmental monitoring.

\section{Fundamentals of membrane diffusion}

\subsection{Quantitation of gas membrane diffusion}

Figure 2a schematically demonstrates the common parameters in gas membrane diffusion. The permeability of a species $i\left(P_{M i}\right)$ refers to the intrinsic ability of a membrane to allow it passage. As shown in Equation (1), the total permeated molar flux of a species $i\left(J_{i}\right)$ is proportional to the $P_{M i}$ and the driving force, described as the pressure gradient $\left(F_{p}\right)$ across the membrane, is inversely proportional to thickness of the membrane $\left(d_{m}\right)$. To simplify, $J_{i}$ is a proportional function of the permeability coefficient $\bar{P}_{M i}$ and corresponding driving force, i.e. $F_{p}$ (Equation 1).

$$
J_{i}=\left(\frac{P_{M i}}{d_{m}}\right) F_{p}=\bar{P}_{M i} F_{p}
$$

Under the same conditions, the selectivity $\left(S_{i, j}\right)$ of two gases (i.e. gas $i$ and $j$ ) can be obtained most simply by the ratio of the single-gas permeability or permeability coefficient, where $P_{M i}$ is the permeability of the more permeable gas and $P_{M j}$ is the permeability of the less permeable gas in the binary gas pair (Equation 2).

$$
S_{i, j}=\frac{P_{M i}}{P_{M j}}=\frac{\bar{P}_{M i}}{\bar{P}_{M j}}
$$

Figure $2 \mathrm{~b}$ illustrates the mass transfer process through the membrane and concentration distribution profile of species $i$. The fundamental expression of such gas diffusion through the membrane can be derived from Fick's first law, which relates the flux of species $i$ to the concentration gradient (i. e. $\Delta C_{i}=C_{i d}-C_{i a}$ ). For simplification, the thickness of diffusion boundary layer (DBL) in both donor phase and acceptor phase are not considered in this general formula. Thus, the gradient can be 
related to the concentration in the donor phase $\left(C_{i d}\right)$ and acceptor phase $\left(C_{i a}\right)$ of the membrane thickness (Equation 3).

$$
J_{i}=-D_{i}(C) \Delta C_{i}=\frac{D_{e, i}}{d_{m}}\left(C_{i d}-C_{i a}\right)
$$

Where, $D_{i}(C)$ is the theoretical diffusion coefficient of species $i$ that may have concentration dependence. Thus, an effective diffusivity, $D_{e, i}$ is used, accounting for the porosity and tortuosity of the membrane. The mass transfer of species $i\left(M_{i}\right)$ across the membrane with an area of $S$ can then be given by Equation 4 where $t$ is contact time of the species $i$ with sensor.

$$
M_{i}=\int_{0}^{t} J_{i} S d t=\int_{0}^{t} \frac{D_{e, i} S}{d_{m}}\left(C_{i d}-C_{i a}\right) d t
$$

When incorporated with different kinds of transducers (see section 3), the detection signal intensity of species $i$ ( $I_{i}$ ) should be related to $M_{i}$, usually in a direct ratio relationship (Equation 5).

$$
I_{i} \propto M_{i}
$$

Usually, in membrane-based sensing devices, the membranes with both high permeability and selectivity are desirable. Higher permeability shortens the response time of gas detection, thereby increasing the efficiency of gas monitoring, while higher selectivity results in low effects of nonanalyte gases [25]. In this regard, it is well-established that functional polymer membranes are able to offer both high permeability and selectivity, and are considered ideal membrane materials to apply in membrane-based sensing devices [26].

\subsection{Molecular Mechanisms of gas membrane diffusion}

Various mechanisms for gas diffusion across membranes have been proposed depending on the properties of both the permeants and the membrane, including bulk poiseuille flow for large pores, 
Knudsen diffusion for intermediate size pores, size-restricted diffusion for small pores, and a solidstate diffusion mechanism for very small or no pores [11, 27-29]. Usually, depending on the conditions and the properties of the permeating molecules, two or more of these processes can occur simultaneously. In practical situations, there will be a range of pore sizes in the membrane, thus the gas permeability is influenced by a combination of these diffusion mechanisms [27]. Figure 3 gives a schematic representation of these gas diffusion mechanisms.

Bulk Poiseuille flow or convective flow (Figure 3a) happens when the pore diameter is larger than the mean free path of the molecules. In this case, gas diffusion is conducted by bulk fluid flow through the large pores. The Hagen-Pouisselle mechanism is used to describe such gas diffusion processes [30]. As the pore is large enough to allow different gas species to permeate, selectivity of such mechanism is relatively poor [31].

The Knudsen diffusion (Figure 3b) predominates in membrane diffusion if the pore diameter is smaller than the mean free path of the gas molecule, where there are more collisions with the pore walls than with other gas molecules [32]. Gas diffusion by Knudsen diffusion occurs in the gaseous state without involvement of membrane adsorption or interaction with the membrane surface, and each molecule moves independent of others $[11,27]$. The Knudsen diffusivity can be obtained from the gas kinetic velocity and geometric parameters associated with the membrane, so the separation of a gas mixture can be expressed by the different velocities of the movement of different gas species caused by the molecular weights of the gases. The selectivity achieved by the Knudsen mechanism is proportional to the square root of the inverse ratio of the molecular weights, but it is still not sufficient for many applications such as selective sensing [29, 33].

The size-restricted diffusion or molecular sieve diffusion (Figure 3c) requires that membranes must contain pores with diameters that are in between those of the different gas molecules, so that only the smaller size molecules can permeate and a very high selectivity would be achieved [11]. In particular, 
size-restricted diffusion can be subdivided into two types: surface diffusion mechanisms and gastranslational mechanisms. The surface diffusion occurs at low temperatures when gas molecules cannot escape from the surface potential field. In this case, gas molecules adsorb onto the surface of the membrane at the pore entrance, diffuse across the membrane, and desorb at the pore exit, as shown in Figure 3c left inset. In contrast, the gas-translational mechanism occurs in membranes with small pore sizes when the diffusing gas molecules have sufficient kinetic energy to escape the surface potential field but are restricted by the presence of a pore wall. This can be considered as a combination of the Knudsen diffusion model and the surface diffusion model, as shown in Figure 3c right inset [34-36]. In general, this size-restricted diffusion mechanism provides the most flexible and attractive choice for the practical separation of gas mixtures, because the selectivity is determined by the preferential adsorption of certain components of the gas mixture on the surface of the membrane pores as well as by the selective diffusion of the absorbed molecules [11]. This allows high selectivity and high permeability for some gas mixture separations, especially for the smaller components of a gas mixture [33, 37]. However, the disadvantage of this mechanism is the blockage of membrane pores caused by the fouling condensable impurities in the gas stream [11].

Solid-state diffusion (Figure 3d) occurs with further decrease in pore size where the gas molecule interacts strongly with the membrane material and its solubility needs to be considered [38, 39]. In this particular mechanism, the mass transport begins with the absorption or adsorption at the upstream boundary, followed by activated diffusion (solubility) through the membrane, and ends in desorption or evaporation on the other side. This solid-state diffusion mechanism is driven by a difference in the thermodynamic activities existing in the donor phase and acceptor phase as well as the interacting force working between the membrane and the permeate molecules. The gas permeability coefficient can be viewed as the product of a solubility coefficient and a diffusion coefficient of the gas molecule [30]. Such a diffusion mechanism is usually designed for special gas 
permeation and high selectivity can be achieved by selecting or synthesising special membrane materials.

\section{Gas sensors based on membrane diffusion}

In the past three decades, more and more gas sensing devices employing membrane diffusion processes have been developed. Traditional direct gas sensing methods, for example ammonia detection methods, often suffer from poor selectivity or low sensitivity [40]. The incorporation of the sensors with the membrane merges the merits of the sensor and the membrane. The membrane-based sensors can effectively resolve these issues by employing a gas permeable membrane to achieve a selection mechanism that allows only the gas of interest to influence the internal recognition component surrounding the detector $[41,42]$. On the one hand, this exclusively qualitative and quantitative chemical or biochemical recognition reaction greatly improves the selectivity of sensors, on the other hand, it can pre-concentrate the gas species by sampling a large volume of the analyte gas into a small volume of internal recognition component (usually liquid) where detectable substance is formed and detected by the transducer, which also enhances detection selectivity and sensitivity [43]. As the membrane is the core component, the problem associate with membrane, e.g. membrane blockage, will affect the accuracy and precision of the measurement. When the sensor is deployed, special attention should be devoted to avoid such an issue [12, 13].

The membrane-based gas sensors can generally be classified into membrane-based gas chemical sensors and membrane-based gas biosensors based on the principle of the internal recognition reactions (i.e. chemical recognition or biochemical recognition). Importantly, internal recognition component can selectively react with diffused gas species and produce measurable forms (such as conductivity, current, voltage or colour) which could be detected by different transducers. In other words, the transducing method can be flexibly selected based on the requirement of different gas diffusion and specific recognition reaction. Currently, electrochemical and optical transducers are the 
most popular transducers incorporated into these membrane-based sensors because of their simple detection principle (i.e. conductivity detection and light intensity measurement), user-friendliness with high reliability and accuracy, easy availability and low cost. Therefore, membrane-based sensors based on chemical and biochemical recognition combined with electrochemical and optical transducers are introduced in sequence as follow.

\subsection{Membrane-based gas chemical sensors}

\subsubsection{Membrane-based electrochemical sensors}

Membrane-based electrochemical sensors mainly include potentiometric sensors for measurement of voltage, amperometric sensors for measurement of current and conductimetric sensors for measurement of conductivity [7]. Figure 4 illustrates the typical configuration of these three kinds of electrochemical sensors.

\subsubsection{Potentiometric sensors}

The detection process of potentiometric sensors is based on the adopted gas permeable membrane permitting the passage of certain analytes from the external sample to the internal electrochemical cell that consists of recognition component (i.e. inner electrolyte), a selective working electrode, and a reference electrode (Figure 4a). The passed gas molecules react with the electrolyte solution and causes corresponding chemical changes, such as the shift of protonation equilibrium and therefore acidity (i.e. $\mathrm{pH}$ ) that can be measured by a selective electrode (e.g. a glass $\mathrm{pH}$-electrode). Commonly, the relationship between potential response and concentration of the analyte species follows the Nernst equation. The concentration of the dissolved analyte form and its corresponding gaseous form obeys Henry’s law [44]. Severinghaus and Bradley developed the first potentiometric gas sensor with polytetrafluoroethylene (PTFE) as the gas permeable membrane for $\mathrm{CO}_{2}$ determination in blood [45] 
Based on these findings, Strickler and Beebe created the first potentiometric ammonia sensor using polyvinyl fluoride as the gas permeable membrane [46].

The functional characteristics of these sensors are strongly related to the selectivity of the gaspermeable membrane and the specific inner electrolyte in which the diffused gas species takes part in an equilibrium involving an ion which can be directly measured by an ion selective electrode [47]. Consequently, the studies on gas permeable membranes and the specific inner electrolyte or ion selective electrode have been rapidly developed and improved in recent years. A microporous hydrophobic membrane system was proposed where any gas species having a measurable vapour pressure over a sample solution will diffuse, and many new solid electrolyte-based sensors as well as a large number of new ion selective electrodes have been developed for specific gas detection [47]. In addition, combined application with flow injection analysis further extends the application of this kind of sensor in industry, medicine, and environment quality control [44]. Table 2 summarizes the classical and developed membrane-based potentiometric gas sensors.

Table 2 Membrane-based potentiometric gas sensors.

\begin{tabular}{|c|c|c|c|c|}
\hline Analyte & Electrode & Detection limit & Sample type & Reference \\
\hline \multirow[t]{2}{*}{$\mathrm{CO}_{2}$} & pH electrode & $\bar{\sim}$ & Gas mixture & [45] \\
\hline & $\begin{array}{l}\text { Bicarbonate-doped polypyrrole } \mathrm{pH} \\
\text { electrode }\end{array}$ & $\sim$ & Water & [48] \\
\hline $\mathbf{O}_{2}$ & $\begin{array}{l}\mathrm{O}_{2} \text { electrode with zirconium dioxide } \\
\text { solid-electrolyte }\end{array}$ & $\sim$ & Gas mixture & [49] \\
\hline \multirow[t]{4}{*}{$\mathrm{NH}_{3}$} & pH electrode & $10^{-5} \mathrm{~mol} \mathrm{~L}^{-1}$ & Water & {$[50]$} \\
\hline & $\begin{array}{c}\text { Ammonium sensitive liquid membrane } \\
\text { electrode }\end{array}$ & $10^{-8} \mathrm{~mol} \mathrm{~L}^{-1}$ & Gas mixture & [44] \\
\hline & $\begin{array}{l}\text { PVC tubular ammonium ion-selective } \\
\text { electrode }\end{array}$ & $5 \times 10^{-4} \mathrm{~mol} \mathrm{~L}^{-1}$ & $\begin{array}{l}\text { Milk and dairy } \\
\text { products }\end{array}$ & [51] \\
\hline & $\begin{array}{l}\text { Tubular ammonium ion-selective } \\
\text { electrode }\end{array}$ & $\sim$ & Soil digests & [52] \\
\hline \multirow[t]{2}{*}{ Cyanide } & Galvanic hydrogen cyanide electrode & $0.1 \mathrm{mg} \mathrm{L}^{-1}$ & Industrial wastewater & {$[53]$} \\
\hline & Metallica silver wire electrode & $\sim$ & Gas mixture & [54] \\
\hline $\mathrm{SO}_{2}$ & $\begin{array}{l}\text { Crystalline iodide double-membrane } \\
\text { tubular electrode }\end{array}$ & $3.2 \mathrm{mg} \mathrm{L}^{-1}$ & Gas mixture & {$[55]$} \\
\hline $\mathbf{H}_{2} \mathrm{~S}$ & $\begin{array}{c}\text { Metallica silver wire electrode/sulphide } \\
\text { electrode }\end{array}$ & $0.5 \mathrm{mg} \mathrm{L}^{-1}$ & Wastewater & {$[44,56]$} \\
\hline \multirow[t]{2}{*}{ Chloride } & Tubular chloride selective electrodes & $0.1 \mathrm{mg} \mathrm{L}^{-1}$ & $\begin{array}{l}\text { Tap and mineral } \\
\text { water }\end{array}$ & {$[57]$} \\
\hline & Chloride selective electrodes & $1 \mathrm{mg} \mathrm{L}^{-1}$ & $\begin{array}{l}\text { Surface, ground, } \\
\text { drinking, wastewater }\end{array}$ & {$[58]$} \\
\hline
\end{tabular}




\subsubsection{Amperometric sensors}

Amperometric gas sensors are also known as voltametric or polarographic sensors. They are a conventional electroanalytical technique embodied in coulometry, voltammetry, and constant potential measurements, and are widely used to identify and quantify electroactive gas species in liquid or gas phase [59]. As shown in Figure 4b, the sensor commonly consists of an amperometric cell and a gas permeable membrane. The amperometric cell encompasses a working electrode, a counter electrode and the recognition component (i.e. electrolyte) in which the two electrodes are immersed. The gas permeable membrane is an interface to enable and control a gas analyte to contact the working electrode where a fast, reversible and redox reaction can occur. When measuring the current generated using such a redox reaction, based on Faraday's Law, at a fixed electrode potential and under certain diffusion-limited conditions, the reaction rate (i.e. the rate of generated sensor signal) is directly proportional to the concentration of the diffusive gas analyte [60].

The first gas permeable membrane combined with an amperometric sensor was invented by Clark who placed a platinum electrode behind a membrane with a thin layer of an indifferent electrolyte interposed between the platinum surface and the membrane. It was designed for measuring $\mathrm{O}_{2}$ that could diffuse through the membrane and then be detected polarographically. Amperometric gas sensors have experienced ever-increasing development of the main sensor parts, i.e. the membrane, electrode and electrolyte, during last the 50 years. The porous hydrophobic poly-membrane (e.g. PTFE) has been widely investigated and selected to fit with modern membrane-based amperometric sensors because of its strict hydrophobic characteristics to prevent being wetted and selective allowance of dissolved gas transport to the working electrode [61]. Further modification of PTFE membranes, like coating with vacuum-evaporated metals for improving sensitivity [62], using nanostructures for optimizing sensor design and controlling mass transfer rates [63, 64] have also been developed. The development of gas-diffusion electrodes greatly promotes amperometric 
sensing techniques based on back-side metallized porous membranes where the real surface area of the electrode is significantly enlarged [61]. This not only makes the mass transfer of analyte faster, resulting in shorter response times and higher sensitivity [60], but also allows species with relatively poor electro-activity to permeate and produce measurable currents [65].

In addition to the progress made in the development of membranes and electrodes, improvements in electrolytes have emerged since the 1970s. Due to limitations in specificity, service life, operating temperature range and electrical potential range associated with conventional aqueous electrolytes, non-aqueous, solid polymer and nanostructures electrolytes were designed and adopted as an alternative electrolyte in many amperometric sensors. These include the earliest non-aqueous electrolyte introduced by Harshad et al. for chlorine detection [66] and the solid polymer electrolyte employed by Yan and Liu for carbon monoxide measurement [67]. These researches and developments constantly improve the robustness and sensitivity of the membrane-based amperometric gas sensors producing shorter response times and longer lifetimes. They also optimize the structure of the sensors for wide practical application in gas detection in industry, the environment and biochemistry. Table 3 summarizes the typical and developed membrane-based amperometric gas sensors.

Table 3 Membrane-based amperometric gas sensors.

\begin{tabular}{|c|c|c|c|c|c|}
\hline Analyte & Method & Electrode & Detection limit & Sample type & Reference \\
\hline$\overline{\mathbf{O}_{2}}$ & Probe & $\begin{array}{l}\text { Gold disc voltametric } \\
\text { microelectrode }\end{array}$ & $10 \%$ & Dry gas mixture & [68] \\
\hline $\mathbf{N}_{2} \mathbf{O}$ & Probe & $\begin{array}{l}\text { Gold disc voltametric } \\
\text { microelectrode }\end{array}$ & $10 \%$ & Dry gas mixture & [68] \\
\hline Ethylene & Probe & $\begin{array}{l}\text { Gold deposited gas- } \\
\text { diffusion electrode }\end{array}$ & $40 \mu g \mathrm{~L}^{-1}$ & $\begin{array}{l}\text { Humidified or dry gas } \\
\text { mixture }\end{array}$ & [69] \\
\hline Ethyl alcohol & Probe & Gold deposited gas- & $2 \mu g \mathrm{~L}^{-1}$ & Humidified or dry gas & [70] \\
\hline Acetaldehyde & Probe & diffusion electrode & $1 \mu g \mathrm{~L}^{-1}$ & mixture & \\
\hline Acetylene & Probe & & $20 \mu \mathrm{g} \mathrm{L}^{-1}$ & & \\
\hline $\mathrm{SO}_{2}$ & Probe & & $0.6 \mu g \mathrm{~L}^{-1}$ & & \\
\hline $\mathrm{SO}_{2}$ & Probe & $\begin{array}{l}\text { Gold deposited gas- } \\
\text { diffusion electrode }\end{array}$ & $\sim$ & $\begin{array}{l}\text { Humidified or dry gas } \\
\text { mixture }\end{array}$ & {$[71]$} \\
\hline $\mathbf{H}_{2}$ & Probe & $\begin{array}{l}\text { Tungsten carbide-based } \\
\text { gas-diffusion electrode }\end{array}$ & $1 \%$ & Gas mixtures & [72] \\
\hline $\mathrm{SO}_{2}$ & FIA & Boron-doped diamond & $0.05 \mathrm{mg} \mathrm{L}^{-1}$ & Wine & [73] \\
\hline
\end{tabular}




\begin{tabular}{|c|c|c|c|c|c|}
\hline Cyanide & FIA & $\begin{array}{c}\text { electrode } \\
\text { Gas-diffusion electrode }\end{array}$ & $10 \mu g \mathrm{~L}^{-1}$ & $\begin{array}{l}\text { Industrial effluents, } \\
\text { waste, ground and } \\
\text { surface water }\end{array}$ & [58] \\
\hline Chloride & FIA & Platinum electrode & $0.1 \mu \mathrm{mol} \mathrm{dm}{ }^{-3}$ & Natural and tap waters & [74] \\
\hline
\end{tabular}

Note: FIA represents flow injection amperometry.

\subsubsection{Conductimetric sensors}

Sensors in this group are based on the measurement of electrical conductivity of a film or bulk solution to determine the quantity of an analyte present in a sample [48]. Fundamentally, such a signal transducer is non-selective as conductivity represents the measure of total ions in the mixture around the conductivity probe (such as the 4-point probe). Therefore, the selectivity of conductimetric sensors needs to be provided by specific chemical recognition components to selectively extract analytes through the gas-permeable membrane. As shown in Figure 4c, the analyte permeates through the membrane to react with selective recognition components, resulting in conductivity changes, which are in turn directly proportional to the amount of permeated gas, i.e. the detection principle of the analyte concentration in the sample mixture.

This method is typically used for detecting inorganic gases especially acidic or alkaline gas (Table 4). In the case of ammonia detection for example, the application of conductimetry to the measurement of ammonia was first demonstrated by Hendricks et al. [75]. Shaw and Staddon then introduced the diffusion cell to transfer ammonia from the sample to sulfuric acid for further conductivity determination [76]. Inspired by automated colorimetric methods, Carlson proposed continuous membrane diffusion flow and conductimetric determination of ammonia [77]. As this selective detection principle does not involve complex chemical reactions and is independent of the sample matrixes, it has been widely used for detecting other gases in flow mode [78]. Therefore, it has become a popular method in gas detection in the food industry, water industry and atmospheric environmental monitoring. 
Table 4 Membrane-based conductimetric gas sensors.

\begin{tabular}{|c|c|c|c|c|c|c|}
\hline Analyte & Method & $\begin{array}{l}\text { Recognition } \\
\text { component }\end{array}$ & $\begin{array}{c}\text { Detection } \\
\text { limit } \\
\end{array}$ & $\begin{array}{c}\text { Sample } \\
\text { throughputs }\end{array}$ & Sample type & Reference \\
\hline \multirow[t]{6}{*}{$\mathrm{NH}_{3}$} & FIC & Deionized water & $\bar{\sim}$ & $60 \mathrm{~h}^{-1}$ & $\begin{array}{c}\text { Kjeldahl digestion } \\
\text { solution }\end{array}$ & [78] \\
\hline & FIC & Deionized water & $1 \mathrm{mg} \mathrm{L}^{-1}$ & $35 \mathrm{~h}^{-1}$ & $\begin{array}{l}\text { Kjeldahl digestion } \\
\text { solution of milk and } \\
\text { chicken meat }\end{array}$ & [79] \\
\hline & FIC & Deionized water & $5 \mathrm{ng} \mathrm{mL}^{-1}$ & $60 \mathrm{~h}^{-1}$ & Water & [80] \\
\hline & FIC & Boric acid & $0.03 \mathrm{mg} \mathrm{L}^{-1}$ & $\sim$ & Wastewater & [81] \\
\hline & FIC & Boric acid & 0.3 vol. $\%$ & $\sim$ & Gas mixture & [82] \\
\hline & SIC & Boric acid & $\begin{array}{c}2.6 \times 10^{-4} \mathrm{~mol} \\
\mathrm{~L}^{-1}\end{array}$ & $3 \mathrm{~h}^{-1}$ & Milk & [83] \\
\hline $\mathrm{SO}_{2}$ & FIC & Deionized water & $0.03 \mathrm{mg} \mathrm{L}^{-1}$ & $120 \mathrm{~h}^{-1}$ & $\begin{array}{l}\text { Wine and fruit } \\
\text { juices }\end{array}$ & [84] \\
\hline Acetic acid & FIC & Deionized water & $0.01 \mathrm{~mol} \mathrm{~L}^{-1}$ & $80 h^{-1}$ & Vinegar & [84] \\
\hline $\begin{array}{c}\text { Total } \\
\text { inorganic } \\
\text { carbon }\end{array}$ & FIC & $\begin{array}{l}\text { Tris (hydroxymethyl) } \\
\text { aminomethane }\end{array}$ & $6 \mu \mathrm{mol} \mathrm{L}{ }^{-1}$ & $15 \mathrm{~h}^{-1}$ & Water & [85] \\
\hline
\end{tabular}

Note: FIC represents flow injection conductimetry; SIC represents sequential injection conductimetry.

\subsubsection{Membrane-based optical sensors}

Optical sensors are another major category of membrane sensors, which are mostly based on spectroscopic analysis, involving techniques of absorption and emission spectrometry [16]. As illustrated in Figure 5, the gas that passes through the membrane reacts with chemical recognition components (such as chromophore or fluorescence reagents) to produce products with a distinctive colour or fluorescence that can be detected by the optical transducers. In the case of the colour change reactions, the Beer-Lambert law is commonly used to quantify the amount of the gas analyte. The incorporation of optical methods generally allow excellent sensitivity, selectivity and reliability [86], but their applications in gas sensors were seriously restricted due to miniaturization and relatively high cost of the optical transducers prior to the 1980 s.

In 1983, Zhang and Rudolf successfully developed a $\mathrm{CO}_{2}$ sensor based on fluorescence with a gas permeable membrane [87]. Subsequently, Arnold and Ostler proposed a fibre optic ammonia sensor which employed the $\mathrm{pH}$ indicator dye ( $p$-nitrophenol) to detect the induced $\mathrm{pH}$ change, and validated that the light absorbance of the $\mathrm{pH}$ change is related to the ammonia concentration [88]. 
Concurrently, Wolfbeis and Posch also verified that the fluorescence intensity of a buffered $\mathrm{pH}$ indicator and an oxygen-sensitive material (a Kieselgel-adsorbed fluorescent metal-organic complex) could be increased when exposing to ammonia and oxygen, respectively, resulting in the emergence of a fibre optic fluorescing ammonia and oxygen sensor [89, 90]. Preininger et al. created the first fibre optic biological oxygen demand (BOD) sensor that could detect up to $110 \mathrm{mg} \mathrm{L}^{-1} \mathrm{BOD}$ with fast response time (5-10 min) by detecting $\mathrm{O}_{2}$ concentration changes in the biochemical process [91].

Recently, increasing research has focused on the development of more effective recognition components for fast selective recognition with low-cost optic fibres. Along this line, numerous membrane-based optical gas sensors with high selectivity, accuracy and reliability have been developed. Table 5 summaries the membrane-based optical sensors for environmental gas detection.

Table 5 Membrane-based optic sensors on common environmental gas detection.

\begin{tabular}{|c|c|c|c|c|c|c|c|}
\hline Analyte & Method & $\begin{array}{c}\text { Detection } \\
\text { wavelength }\end{array}$ & $\begin{array}{c}\text { Recognition } \\
\text { component }\end{array}$ & $\begin{array}{c}\text { Detection } \\
\text { limit } \\
\end{array}$ & $\begin{array}{l}\text { Throughputs/ } \\
\text { response time }\end{array}$ & Sample type & Reference \\
\hline \multirow[t]{2}{*}{$\overline{\mathrm{CO}_{2}}$} & FIO & $554 \mathrm{~nm}$ & $\begin{array}{l}\text { Mixed acid/base } \\
\text { indicator }\end{array}$ & $\begin{array}{c}2.50 \times 10^{2} \mu \mathrm{g} \\
\mathrm{L}^{-1}\end{array}$ & $28 h^{-1}$ & $\begin{array}{l}\text { Natural gas } \\
\text { mixture }\end{array}$ & [92] \\
\hline & Probe & $620 \mathrm{~nm}$ & $\begin{array}{l}\text { Mixed acid/base } \\
\text { indicator }\end{array}$ & $\sim$ & $11-26 \min$ & Seawater & [93] \\
\hline $\begin{array}{l}\text { Nitrate/ } \\
\mathrm{NO}_{2}\end{array}$ & FIO & $563 \mathrm{~nm}$ & Colour reagent & $0.5 \mathrm{mg} \mathrm{L}^{-1}$ & $30 h^{-1}$ & $\begin{array}{c}\text { Wastewater } \\
\text { and meat } \\
\text { extracts }\end{array}$ & {$[94]$} \\
\hline $\mathrm{H}_{2} \mathrm{~S} / \mathrm{SO}_{2}$ & FIO & $330 \mathrm{~nm}$ & $\begin{array}{l}\text { o-phthalaldehyde } \\
\text { (OPA) }\end{array}$ & $\sim$ & $\sim$ & $\begin{array}{l}\text { Water and } \\
\text { wine }\end{array}$ & [95] \\
\hline \multirow[t]{3}{*}{$\mathrm{NH}_{3}$} & Probe & $590 \mathrm{~nm}$ & Colorimetric dye & $\sim$ & $15 \mathrm{~s}$ & Gas mixture & [96] \\
\hline & FIO & $565 \mathrm{~nm}$ & $\begin{array}{l}\mathrm{NaCl} \text { solution with } \\
\text { phenol red }\end{array}$ & $0.05 \mu \mathrm{mol} \mathrm{L}-1$ & $60 \mathrm{~h}^{-1}$ & Seawater & [97] \\
\hline & FIO & $690 \mathrm{~nm}$ & Tris/HCl buffer & $\begin{array}{c}2 \times 10^{-7} \mathrm{~mol} \\
\mathrm{~L}^{-1}\end{array}$ & $\sim$ & water & [98] \\
\hline Cyanide & FIO & $510 \mathrm{~nm}$ & $\begin{array}{c}\text { Ninhydrin in } \\
\text { carbonate medium }\end{array}$ & $2.5 \mu \mathrm{g} \mathrm{L}^{-1}$ & $\sim$ & wastewater & [99] \\
\hline
\end{tabular}

Note: FIO represents flow injection optic method.

\subsection{Membrane-based gas biosensors}

Membrane-based gas biosensors commonly combine a biological recognition mechanism that is more selective than chemical recognition processes due to the involvement of highly selective 
biochemical reactions. Similar to the previous section, two types of membrane-based gas biosensors, with electrochemical and optical transducers, are briefly reviewed below.

The typical configurations of these two kinds of membrane-based biosensors are shown in Figure 6a and 6b. The gas permeable membrane is used for controlling the gas transportation, and the biochemical recognition component, as the key component in the biosensor, is used for absorbing and reacting with permeated gas species to produce the electrical signal measured by electrochemical or optical transducers. Sometimes, the biochemical recognition component can be thinly immobilized on the membrane.

The advantages of biosensor detection methods include high selectivity and sensitivity, miniaturization, and uniform whole structures featuring direct transduction with no sample preparation, make it applicable to both laboratory-based and field-based environmental analyses [100, 101]. Based on the concentration range, reusability or renewability, accuracy, and reproducibility requirements, the biosensors have been developed for groundwater monitoring, drinking water analysis, and the rapid analysis of extracts of soils and sediments at hazardous waste sites [102]. Table 6 summarizes some applications of membrane-based electrochemical and optical biosensors.

\subsubsection{Membrane-based electrochemical biosensors}

A membrane-based electrochemical biosensor is a small analytical device linking a biochemical recognition component with an electrochemical transducer (amperometry, potentiometry and conductimetry). The biochemical recognition component translates the analyte concentration into chemical or physical changes, and the transducer converts the changes to a measurable electrical signal for quantitatively detecting the analyte. The biochemical recognition components play a vital role in selectively recognizing gas analytes, usually containing enzymes, bacteria, cells, and antibodies. Enzyme biosensors are the most extensive researched, they often employ amperometrical or potentiometrical transducers to monitor the changes caused by the product of bio-catalytic 
reactions between enzymes and target analytes [103]. Environmental pollutants like parathion, nitrate, and formaldehyde can be detected by this kind of biosensor using sulphite parathion hydrolase, nitrate reductase, and formaldehyde dehydrogenase, respectively [104-107]. The second major category is antibody biosensors or immunosensors, based on the principle that antigen-antibody interactions can be transduced directly into a measurable electrochemical signal. These biosensors are usually applied in clinical and medical areas [108].

\subsubsection{Membrane-based optical biosensors}

Similar to the working principle of an electrochemical biosensor, a membrane-based optical biosensor employs an optical (spectrophotometry and fluorometry) transducer to convert the biological changes into a measurable light signal. As an example, bioluminescent bacteria are often used as a biochemical recognition component for rapid detection of toxic gases such as benzene vapour [109]. Other biosensors employ part of a cell, the whole cell or a modified cell as a biochemical recognition component. These biosensors include liposome biosensors, whole-cell biosensors and whole-cell biochip biosensors, have been found useful in monitoring organic environmental pollutants such as triazine pesticides, chlorsulfuron herbicides and aromatic hydrocarbons [103, 110].

Table 6 Membrane-based electrochemical and optical gas biosensors.

\begin{tabular}{|c|c|c|c|c|c|c|}
\hline Analyte & Method & $\begin{array}{c}\text { Biochemical recognition } \\
\text { component }\end{array}$ & Transducer & $\begin{array}{l}\text { Detection } \\
\text { limit }\end{array}$ & Sample type & Reference \\
\hline Formaldehyde & FIEB & Formaldehyde dehydrogenase & Amperometry & $1.5 \mathrm{ng} \mathrm{mL}^{-1}$ & $\begin{array}{l}\text { Aqueous } \\
\text { solution }\end{array}$ & {$[111]$} \\
\hline & Probe & Formaldehyde dehydrogenase & Amperometry & $2 \mu g \mathrm{~L}^{-1}$ & Gas matrix & [112] \\
\hline Ethanol & Probe & Alcohol oxidase enzyme & Amperometry & $0.36 \mathrm{mg} \mathrm{L}^{-1}$ & Gas matrix & [113] \\
\hline Nerve agents & Probe & Butyrylcholinesterase & Amperometry & $12 \mu g \mathrm{~L}^{-1}$ & Sarin gas & {$[114]$} \\
\hline Phenol & Probe & Tyrosinase enzyme & Amperometry & $22 \mu \mathrm{g} \mathrm{L}^{-1}$ & Gas matrix & {$[115]$} \\
\hline Ethanol & Probe & Yeast cell & Potentiometry & $\sim$ & $\begin{array}{l}\text { Alcoholic } \\
\text { beverages }\end{array}$ & [116] \\
\hline $\mathbf{N H}_{3}$ & FIEB & $\begin{array}{l}\text { Cellulose triacetate membrane } \\
\text { containing nonactin }\end{array}$ & Potentiometry & $10 \mu \mathrm{mol} \mathrm{L}{ }^{-1}$ & Blood serum & {$[117]$} \\
\hline $\begin{array}{l}\text { Benzene } \\
\text { vapour }\end{array}$ & Probe & Bioluminescent bacteria & $\begin{array}{l}\text { Optical } \\
\text { detection }\end{array}$ & 0.2 vol. $\%$ & Gas matrix & [109] \\
\hline Ethanol & Probe & Alcohol dehydrogenase & $\begin{array}{c}\text { Optical } \\
\text { detection }\end{array}$ & $\sim$ & $\begin{array}{l}\text { Aqueous } \\
\text { solution }\end{array}$ & [118] \\
\hline NO & Probe & Protein doped sol-gel thin film & Optical & $1 \mathrm{mg} \mathrm{L}^{-1}$ & Gas matrix & [119] \\
\hline
\end{tabular}




\begin{tabular}{lccccc}
\hline 4-chlorophenol & Probe & $\begin{array}{c}\text { Freeze-dried recombinant } \\
\text { bioluminescent bacteria }\end{array}$ & $\begin{array}{c}\text { detection } \\
\text { Optical } \\
\text { detection }\end{array}$ & $50 \mathrm{mg} \mathrm{L}^{-1}$ & $\begin{array}{c}\text { Aqueous } \\
\text { solution }\end{array}$ \\
\hline
\end{tabular}

Note: FIEB represents flow injection electrochemical biosensor.

\section{Trends in membrane-based gas sensors development}

Currently, a larger number of membrane-based gas sensing devices have been developed. The detection of the dissolved gas species can be achieved either in immersion sampling mode or flow sampling mode. The immersion mode is often used by probe sensors that may be deployed into the grab and pre-treated samples or real samples, such as for direct measurement or in-situ measurement, respectively. Some developed $\mathrm{NH}_{3}$ sensors $[50,96]$ and $\mathrm{CO}_{2}$ sensors $[48,93]$ belong to this group. In comparison, the flow sampling mode refers to employing a manifold with a pump and an injector to direct the non-treated or pre-treated sample into the detection device, which is commonly termed to flow injection analysis (FIA). Many developed gas sensing techniques, as detectors, are combined with FIA. For example, detection of ammonia can be achieved by sequential flow injection with a membrane-based spectrophotometric detector [83] and determination of cyanides can be carried out by a gas diffusion flow injection analysis [99].

The conventional membrane-based detection techniques, either immersion or flow sampling mode, achieve detection by obtaining a steady detection signal that represents the average concentration within a certain period or in certain volume of sample. The dynamic changes of analytical signals reflect the dynamically changed analyte concentration but they are often neglected due to difficulty in obtaining the exact values of such signal changes. Although single point measurement is important for many production processes such as gas emergency detection, periodical spot checks and other non-continuous detection purposes, it is more important to achieve real-time continuous gas monitoring to comprehensively investigate dynamic backgrounds of gas concentration distribution and migration. This is important in many fields, such as environmental protection by identifying the 
pattern of greenhouse gas emission, optimization of fertilizer utilization by studying dynamic patterns of ammonia volatilization, and avoiding economic losses by real-time event detection and alarming in many industrial production processes. Therefore, the achievement of real-time and continuous gas monitoring is a significant research direction.

In order to achieve real-time and continuous detection, the recognition reactions involved must be fast enough to instantaneously convert all permeated analyte into the products that can be real-time detected by the advanced transducing and computing technology. The analyte concentration in the acceptor phase, $C_{i a}$, should be zero, so Equation (4) can be transferred into Equation (6). Based on Equation (5) and (6), the change rate of the detection signal within time $t$ should be proportional to the analyte concentration in the donor phase, $C_{i d}$, as shown in Equation (7) [8].

$$
\begin{gathered}
M_{i}=\int_{0}^{t} J_{i} S d t=\int_{0}^{t} \frac{D_{e, i} S}{d_{m}}\left[C_{i d}\right] d t \\
\frac{d I_{i}}{d t} \propto \frac{D_{e, i} S}{d_{m}}\left[C_{i d}\right]
\end{gathered}
$$

It is well-established that the chemical composition of membrane, membrane pore sizes, membrane compaction degree, membrane porosity and tortuosity, and membrane thickness would affect the selectivity and sensitivity of the gas sensors as they influence kinetics of the diffusion process [121]. Usually, the membranes employed in membrane-diffusion based gas sensors are mainly hydrophobic Polytetrafluoroethylene (PTFE) membranes, also named Teflon membranes, that has been adopted by a wild range of gas sensors, such as $\mathrm{CO}_{2}$ sensors [48, 92-93], $\mathrm{SO}_{2}$ sensors [73, 84], and $\mathrm{NH}_{3}$ sensors $[79,83,96]$, mainly because they are inert to permeated gas and sample matrix, permeable to gas analyte and impermeable to liquid sample matrix. The larger pore size of membrane results in larger $D_{e, i}$ value in Equation 7 [122], on the contrary, the larger thickness of membrane $d_{m}$ leads to the slower mass transfer across the membrane [123]. Moreover, the reduction in membrane porosity 
would cause decrease in $D_{e, i}$ [124], and higher tortuosity caused by high degree of membrane compaction would lead to lower $d_{m}$ [121]. Fortunately, for a certain membrane (with fixed pore size, thickness, porosity and tortuosity) used in one gas sensor, the $D_{e, i}$ and $d_{m}$ are commonly kept constant in the gas detection process. According to Equation 7, this rectifies that the real-time change rate of signal response is proportional to the real-time gas concentration. Importantly, this makes it a direct and absolute method for dynamic real-time monitoring. With the incorporation of this membrane diffusion mechanism, rapid-response transducers, fast sampling and advanced computing electronic techniques, it can be predicted that the real-time continuous gas monitoring will prevail in the next generation of environmental monitoring of pollutants and process monitoring of critical intermediates and products.

In fact, current available membrane-based sensors have confirmed this trend to some extent. Figure 7a demonstrates one typical fibre optic membrane-based ammonia probe and its response curve [88]. It employed the $\mathrm{pH}$ indicator dye ( $p$-nitrophenol) to detect $\mathrm{pH}$ changes of an internal electrolyte solution. In the detection process, gaseous ammonia diffuses across the gas-permeable membrane until the ammonia partial pressure is equal on both sides. The variation of the ammonia concentration in the internal electrolyte solution causes a change in $\mathrm{pH}$ which alters the relative concentration ratio of the two forms of the $\mathrm{pH}$ indicator dye (p-nitrophenol and nonprotonated species). Therefore, an increase in ammonia concentration results in a larger amount of the chromophore, which is measured as a decrease in the intensity of the monitored radiation or an increase in absorbance. Based on Henry's law and the Beer-Lambert law, the measured absorbance at $404 \mathrm{~nm}$ under steady-state conditions, $A_{404}$, is proportional to the sample ammonia concentration, $\left[\mathrm{NH}_{3}\right]_{s}$ (Equation 8),

$$
A_{404}=\frac{\epsilon b_{a v e} K_{a}^{I n} C_{I n}}{K_{a}^{a m m} C_{a m m}}\left[N H_{3}\right]_{S}
$$


Where, $\epsilon$ is the molar absorptivity for the nonprotonated species at $404 \mathrm{~nm}, b_{\text {ave }}$ is the average path length for the sensor, $K_{a}^{I n}$ and $K_{a}^{a m m}$ are the acid dissociation constants for the indicator and ammonia, respectively. $C_{a m m}$ and $C_{I n}$ are the total ammonia nitrogen and the total indicator concentrations in the internal electrolyte solution, respectively.

In such a typical example, Equation 8 is obtained under current transducing and computing techniques, which formally coincides with the predicted Equation 7 where detection signal is directly proportional to the analyte concentration. However, the most obvious difference between these two equations is the consideration of time change, i.e. Equation 8 describes the quantitative relationship at one point in time (steady-state mode) while Equation 7 takes time period (dynamic-state mode) into account. The main reason for this difference is the recognition reaction involved in this ammonia probe is reversible and not fast enough to convert all the permeated analyte instantaneously into products that can be detected, resulting in the inability to achieve continuous real-time measurement. Similarly, Figure $7 \mathrm{~b}$ illustrates one typical optical membrane-based flow-through $\mathrm{NO}_{2}$ sensor and the detector readout for a complete measurement cycle [94]. Nonlinear decrease of transmission implied that the involved reactions or transducing frequency were not fast either. Compared with previous ammonia probe, waiting for reaction equilibrium is not necessary for this flow-through sensor. Instead, strict control of equal reaction time can make all measurements comparable, which shortens the response time to some degree.

In general, membrane-based sensors are very promising for continuous real-time monitoring of gas analytes, but there is still the fundamental challenge remaining and has to be considered throughout the selection of membrane, the design of cell structure and choice of signal transducers. In particular, 1) The recognition reaction should be a fast reaction that assures all the permeated target gas analyte $i$ is consumed in a timely fashion. That means the concentration of species $i$ in the signal generating chamber is ideally zero. This establishes a linear relationship between the signal and the gas 
concentration in the sample. 2) The selection of reliable, miniature and fast-response signal detector is also important. Fortunately, with the rapid development of modern electric and computing technology, a wide range of signal transducers such as electrochemical probes, conductometric sensor and optic fibres with sensitive detection limit and fast response time is widely available. 3) The development of crucial protocol to automatically calibrate the membrane diffusion coefficient throughout the detection process due to the change of potential effect factor such as temperature, $\mathrm{pH}$ and salinity. Predictably, membrane-based gas sensors will be significant research direction in the development of new generation of gas sensors for continuous, real-time monitoring.

\section{Summary}

The membrane employed in the membrane-based sensor is able to separate the recognition components from the external sample environment. The selectivity of membrane-based sensing devices can be achieved by the selective passage of the gaseous analyte through the membrane and the chemical or biochemical recognition reactions with the internal components. This work reviews the gas diffusion mechanism across the membrane and quantitative analytical principles of membrane-based sensors. Based on the chemical or biochemical recognition principle, this review introduces a wide range of membrane-based sensing devices, including electrochemical sensors, optical sensors and biosensors, and systematically summarises their applications in monitoring gas analytes (such as $\mathrm{CO}_{2}, \mathrm{O}_{2}, \mathrm{NH}_{3}$, and $\mathrm{SO}_{2}$ ) in the environment. Most importantly, it can be envisages that the rapid development of modern transducers, communication and computing technology will allow low-cost, rapid, in-situ and real-time measurement of diffusion rates of gas analytes for environmental monitoring in the near future. 


\section{Acknowledgements}

Tianling Li acknowledges the PhD scholarships from Griffith University. We thank the financial support from Australia Research Council.

\section{Reference}

[1] M.A. Shannon, P.W. Bohn, M. Elimelech, J.G. Georgiadis, B.J. Mariñas, A.M. Mayes, Science and technology for water purification in the coming decades, Nature, 452(2008) 301-10.

[2] G. Ciardelli, L. Corsi, M. Marcucci, Membrane separation for wastewater reuse in the textile industry, Resources, Conservation and Recycling, 31(2001) 189-97.

[3] D.F. Stamatialis, B.J. Papenburg, M. Gironés, S. Saiful, S.N. Bettahalli, S. Schmitmeier, et al., Medical applications of membranes: drug delivery, artificial organs and tissue engineering, Journal of Membrane Science, 308(2008) 1-34.

[4] A.K. Pabby, S.S. Rizvi, A.M.S. Requena, Handbook of membrane separations: chemical, pharmaceutical, food, and biotechnological applications: CRC Press; 2015.

[5] P. Bernardo, E. Drioli, G. Golemme, Membrane gas separation: a review/state of the art, Industrial \& Engineering Chemistry Research, 48(2009) 4638-63.

[6] C.G.a. Pinto, M.E.F. Laespada, J.L.P. Pavón, B.M. Cordero, Analytical applications of separation techniques through membranes, Laboratory Automation \& Information Management, 34(1999) 11530.

[7] C.K. Ho, M.T. Itamura, M. Kelley, R.C. Hughes, Review of chemical sensors for in-situ monitoring of volatile contaminants, Sandia Report, (2001).

[8] K. Toda, Trends in atmospheric trace gas measurement instruments with membrane-based gas diffusion scrubbers, Analytical Sciences, 20(2004) 19-27.

[9] H. Strathmann, Membrane separation processes, Journal of Membrane Science, 9(1981) 121-89.

[10] N. Van de Merbel, J. Hageman, U.T. Brinkman, Membrane-based sample preparation for chromatography, Journal of Chromatography A, 634(1993) 1-29.

[11] P. Pandey, R. Chauhan, Membranes for gas separation, Progress in Polymer Science, 26(2001) 853-93.

[12] L. Moskvin, T. Nikitina, Membrane methods of substance separation in analytical chemistry, Journal of Analytical Chemistry, 59(2004) 2-16.

[13] J. De Jong, R. Lammertink, M. Wessling, Membranes and microfluidics: a review, Lab on a Chip, 6(2006) 1125-39.

[14] X. Chen, H. Wu, C. Mao, G.M. Whitesides, A prototype two-dimensional capillary electrophoresis system fabricated in poly (dimethylsiloxane), Analytical Chemistry, 74(2002) 1772-8. [15] K. Hylton, S. Mitra, Automated, on-line membrane extraction, Journal of Chromatography A, 1152(2007) 199-214.

[16] X. Liu, S. Cheng, H. Liu, S. Hu, D. Zhang, H. Ning, A survey on gas sensing technology, Sensors, 12(2012) 9635-65.

[17] N.S. Lawrence, Analytical detection methodologies for methane and related hydrocarbons, Talanta, 69(2006) 385-92.

[18] M.T. Ravanchi, T. Kaghazchi, A. Kargari, Application of membrane separation processes in petrochemical industry: a review, Desalination, 235(2009) 199-244.

[19] R. Moos, A brief overview on automotive exhaust gas sensors based on electroceramics, International Journal of Applied Ceramic Technology, 2(2005) 401-13. 
[20] A.G. Shrivas, R. Bavane, A. Mahajan, Electronic nose: A toxic gas sensor by polyaniline thin film conducting polymer, Physics of Semiconductor Devices, International Workshop on IEEE, 2007, 621-3.

[21] K. Ariga, S. Ishihara, H. Abe, M. Li, J.P. Hill, Materials nanoarchitectonics for environmental remediation and sensing, Journal of Materials Chemistry, 22(2012) 2369-77.

[22] B. Ding, M. Yamazaki, S. Shiratori, Electrospun fibrous polyacrylic acid membrane-based gas sensors, Sensors and Actuators B: Chemical, 106(2005) 477-83.

[23] M. Zimmer, J. Erzinger, C. Kujawa, C.-S. Group, The gas membrane sensor (GMS): a new method for gas measurements in deep boreholes applied at the $\mathrm{CO}_{2}$ sink site, International Journal of Greenhouse Gas Control, 5(2011) 995-1001.

[24] S. Neethirajan, D. Jayas, S. Sadistap, Carbon dioxide $\left(\mathrm{CO}_{2}\right)$ sensors for the agri-food industrya review, Food and Bioprocess Technology, 2(2009) 115-21.

[25] B.D. Freeman, Basis of permeability/selectivity tradeoff relations in polymeric gas separation membranes, Macromolecules, 32(1999) 375-80.

[26] N. Du, H.B. Park, M.M. Dal-Cin, M.D. Guiver, Advances in high permeability polymeric membrane materials for $\mathrm{CO}_{2}$ separations, Energy \& Environmental Science, 5(2012) 7306-22.

[27] S.T. Oyama, M. Yamada, T. Sugawara, a. Takagaki, R. Kikuchi, Review on mechanisms of gas permeation through inorganic membranes, Journal of the Japan Petroleum Institute, 54(2011) 298309.

[28] Y. Yampolskii, Polymeric gas separation membranes, Macromolecules, 45(2012) 3298-311.

[29] W. Koros, G. Fleming, Membrane-based gas separation, Journal of Membrane Science, 83(1993) $1-80$.

[30] G. Maier, Gas separation with polymer membranes, Angewandte Chemie International Edition, 37(1998) 2960-74.

[31] P.M. Budd, K.J. Msayib, C.E. Tattershall, B.S. Ghanem, K.J. Reynolds, N.B. McKeown, et al., Gas separation membranes from polymers of intrinsic microporosity, Journal of Membrane Science, 251(2005) 263-9.

[32] J. Gilron, A. Soffer, Knudsen diffusion in microporous carbon membranes with molecular sieving character, Journal of Membrane Science, 209(2002) 339-52.

[33] R.E. Kesting, A. Fritzsche, Polymeric gas separation membranes: Wiley-Interscience; 1993.

[34] A. Shelekhin, A. Dixon, Y. Ma, Theory of gas diffusion and permeation in inorganic molecularsieve membranes, AIChE Journal, 41(1995) 58-67.

[35] T. Yoshioka, E. Nakanishi, T. Tsuru, M. Asaeda, Experimental studies of gas permeation through microporous silica membranes, AIChE journal, 47(2001) 2052-63.

[36] H.R. Lee, M. Kanezashi, Y. Shimomura, T. Yoshioka, T. Tsuru, Evaluation and fabrication of pore-size-tuned silica membranes with tetraethoxydimethyl disiloxane for gas separation, Aiche Journal, 57(2011) 2755-65.

[37] M. Rao, S. Sircar, Nanoporous carbon membranes for separation of gas mixtures by selective surface flow, Journal of Membrane Science, 85(1993) 253-64.

[38] J.S. Masaryk, R.M. Fulrath, Diffusivity of helium in fused silica, The Journal of Chemical Physics, 59(1973) 1198-202.

[39] P.L. Studt, J.F. Shackelford, R.M. Fulrath, Solubility of gases in glass-a monatomic model, Journal of Applied Physics, 41(1970) 2777-80.

[40] B. Timmer, W. Olthuis, A.v.d. Berg, Ammonia sensors and their applications-a review, Sensors and Actuators B: Chemical, 107(2005) 666-77.

[41] S.-I. Ohira, K. Toda, S.-I. Ikebe, P.K. Dasgupta, Hybrid microfabricated device for field measurement of atmospheric sulfur dioxide, Analytical chemistry, 74(2002) 5890-6.

[42] J.W. Erisman, R. Otjes, A. Hensen, P. Jongejan, P. van den Bulk, A. Khlystov, et al., Instrument development and application in studies and monitoring of ambient ammonia, Atmospheric Environment, 35(2001) 1913-22. 
[43] C.B. Boring, R. Al-Horr, Z. Genfa, P.K. Dasgupta, M.W. Martin, W.F. Smith, Field measurement of acid gases and soluble anions in atmospheric particulate matter using a parallel plate wet denuder and an alternating filter-based automated analysis system, Analytical Chemistry, 74(2002) 1256-68.

[44] W. Frenzel, Gas-diffusion separation and flow injection potentiometry, Fresenius' Journal of Analytical Chemistry, 336(1990) 21-8.

[45] J.W. Severinghaus, A.F. Bradley, Electrodes for blood $\mathrm{pO}_{2}$ and $\mathrm{pCO}_{2}$ determination, Journal of Applied Physiology, 13(1958) 515-20.

[46] A.Strickler and C.H. Beebe, Ammonia sensor, US Patent No. 3649505, 1972.

[47] J. Ross, J. Riseman, J. Krueger, Potentiometric gas sensing electrodes, Pure and Applied Chemistry, 36(1973) 473-87.

[48] B.J.V. Tongol, C.A. Binag, F.B. Sevilla Iii, Surface and electrochemical studies of a carbon dioxide probe based on conducting polypyrrole, Sensors and Actuators B: Chemical, 93(2003) 18796.

[49] H. Dietz, Gas-diffusion-controlled solid-electrolyte oxygen sensors, Solid State Ionics, 6(1982) 175-83.

[50] M.E. Meyerhoff, Polymer membrane electrode based potentiometric ammonia gas sensor, Analytical Chemistry, 52(1980) 1532-4.

[51] J.F. Lima, C. Delerue-Matos, M.C. Vaz, Flow-injection analysis of Kjeldahl nitrogen in milk and dairy products by potentiometric detection, Analytica Chimica Acta, 385(1999) 437-41.

[52] A. Ferreira, J. Lima, A. Rangel, Potentiometric determination of total nitrogen in soils by flow injection analysis with a gas-diffusion unit, Soil Research, 34(1996) 503-10.

[53] H. Hachiya, S. Ito, Y. Fushinuki, T. Masadome, Y. Asano, T. Imato, Continuous monitoring for cyanide in waste water with a galvanic hydrogen cyanide sensor using a purge system, Talanta, 48(1999) 997-1004.

[54] W. Frenzel, C.Y. Liu, J. Oleksy-Frenzel, Enhancement of sensors selectivity by gas-diffusion separation, Analytica Chimica Acta, 233(1990) 77-84.

[55] A.N. Araujo, C.M. Couto, J.L. Lima, M.C. Montenegro, Determination of $\mathrm{SO}_{2}$ in wines using a flow injection analysis system with potentiometric detection, Journal of Agricultural and Food Chemistry, 46(1998) 168-72.

[56] K. Brunt, Rapid determination of sulfide in waste waters by continuous flow analysis and gas diffusion and a potentiometric detector, Analytica Chimica Acta, 163(1984) 293-7.

[57] W. Frenzel, Application of flow injection potentiometry to the determination of chloride in various matrices, Fresenius' Zeitschrift für analytische Chemie, 335(1989) 931-7.

[58] M. Miró, W. Frenzel, What flow injection has to offer in the environmental analytical field, Microchimica Acta, 148(2004) 1-20.

[59] Z. Cao, W.J. Buttner, J.R. Stetter, The properties and applications of amperometric gas sensors, Electroanalysis, 4(1992) 253-66.

[60] J.R. Stetter, J. Li, Amperometric gas sensors a review, Chemical reviews, 108(2008) 352-66.

[61] R. Knake, P. Jacquinot, A.W.E. Hodgson, P.C. Hauser, Amperometric sensing in the gas-phase, Analytica Chimica Acta, 549(2005) 1-9.

[62] M. Wienecke, M.-C. Bunescu, M. Pietrzak, K. Deistung, P. Fedtke, PTFE membrane electrodes with increased sensitivity for gas sensor applications, Synthetic Metals, 138(2003) 165-71.

[63] J. Stetter, G. Maclay, Carbon nanotubes and sensors, Advanced micro and nano systems (Baltes et al, eds), (2004).

[64] J.-S. Do, K.-J. Wu, M.-L. Tsai, Amperometric NO gas sensor in the presence of diffusion barrier: selectivity, mass transfer of NO and effect of temperature, Sensors and Actuators B: Chemical, 86(2002) 98-105.

[65] H. Bay, K. Blurton, H. Lieb, H. Oswin, Electrochemical measurements of blood alcohol levels, Nature, 240(1972) 52-3. 
[66] H. Tataria, A.A. Schneider, W.A. Travers Jr, L.E. Martin, Gold and platinum black electrodes, propylene carbonate of g-butyrolactone solvent, Google Patents1980.

[67] H. Yan, C.-C. Liu, A solid polymer electrolyte-bases electrochemical carbon monoxide sensor, Sensors and Actuators B: Chemical, 17(1994) 165-8.

[68] H. McPeak, C.E.W. Hahn, The development of new microelectrode gas sensors: an odyssey. Part III. O2 and N2O reduction at unshielded and membrane-covered gold microdisc electrodes, Journal of Electroanalytical Chemistry, 427(1997) 179-88.

[69] L.R. Jordan, P.C. Hauser, G.A. Dawson, Amperometric Sensor for Monitoring Ethylene, Analytical Chemistry, 69(1997) 558-62.

[70] A.W.E. Hodgson, P. Jacquinot, L.R. Jordan, P.C. Hauser, Amperometric gas sensors with detection limits in the low ppb range, Analytica Chimica Acta, 393(1999) 43-8.

[71] C.Y. Chiou, T.C. Chou, Amperometric sulfur dioxide sensors using the gold deposited gasdiffusion electrode, Electroanalysis, 8(1996) 1179-82.

[72] V. Nikolova, I. Nikolov, P. Andreev, V. Najdenov, T. Vitanov, Tungsten carbide-based electrochemical sensors for hydrogen determination in gas mixtures, Journal of Applied Electrochemistry, 30(2000) 705-10.

[73] C. Chinvongamorn, K. Pinwattana, N. Praphairaksit, T. Imato, O. Chailapakul, Amperometric determination of sulfite by gas diffusion-sequential injection with boron-doped diamond electrode, Sensors, 8(2008) 1846-57.

[74] S.D. Nikolić, E.B. Milosavljević, J.L. Hendrix, J.H. Nelson, Indirect determination of chloride by gas-diffusion flow injection with amperometric detection, Analyst, 116(1991) 49-52.

[75] R. Hendricks, M. Thomas, M. Stout, B. Tolman, Conductometric determination of ammonia application to nitrogen distribution studies, Industrial \& Engineering Chemistry Analytical Edition, 14(1942) 23-6.

[76] J. Shaw, B. Staddon, A conductimetric method for the estimation of small quantities of ammonia, Journal of Experimental Biology, 35(1958) 85-95.

[77] R.M. Carlson, Automated separation and conductimetric determination of ammonia and dissolved carbon dioxide, Analytical Chemistry, 50(1978) 1528-31.

[78] C. Pasquini, L.C. De Faria, Flow-injection determination of ammonia in Kjeldahl digests by gas diffusion and conductometry, Analytica Chimica Acta, 193(1987) 19-27.

[79] J. Junsomboon, J. Jakmunee, Flow injection conductometric system with gas diffusion separation for the determination of Kjeldahl nitrogen in milk and chicken meat, Analytica Chimica Acta, 627(2008) 232-8.

[80] L.C. de Faria, C. Pasquini, Flow-injection determination of inorganic forms of nitrogen by gas diffusion and conductimetry, Analytica Chimica Acta, 245(1991) 183-90.

[81] A. Cerda, M. Oms, R. Forteza, V. Cerda, Evaluation of flow injection methods for ammonium determination in wastewater samples, Analytica Chimica Acta, 311(1995) 165-73.

[82] V. Kubáň, Conductimetric Gas separation-flow injection determination of ammonia in gaseous process streams, Collection of Czechoslovak Chemical Communications, 62(1997) 609-19.

[83] M. Reis Lima, S.M. Fernandes, A.O. Rangel, Enzymatic determination of urea in milk by sequential injection with spectrophotometric and conductometric detection, Journal of Agricultural and Food Chemistry, 52(2004) 6887-90.

[84] C.T. Araújo, J.L. de Carvalho, D.R. Mota, C. De Araujo, N. Coelho, Determination of sulphite and acetic acid in foods by gas permeation flow injection analysis, Food Chemistry, 92(2005) 765-70. [85] Z. Hoherčáková, F. Opekar, A contactless conductivity detection cell for flow injection analysis: Determination of total inorganic carbon, Analytica Chimica Acta, 551(2005) 132-6.

[86] R. Rubio, J. Santander, L. Fonseca, N. Sabate, I. Gracia, C. Cane, et al., Non-selective NDIR array for gas detection, Sensors and Actuators B: Chemical, 127(2007) 69-73.

[87] Z. Zhujun, W.R. Seitz, A carbon dioxide sensor based on fluorescence, Analytica Chimica Acta, 160(1984) 305-9. 
[88] M.A. Arnold, T.J. Ostler, Fiber optic ammonia gas sensing probe, Analytical Chemistry, 58(1986) 1137-40.

[89] O.S. Wolfbeis, H.E. Posch, Fibre-optic fluorescing sensor for ammonia, Analytica Chimica Acta, 185(1986) 321-7.

[90] O.S. Wolfbeis, L.J. Weis, M.J.P. Leiner, W.E. Ziegler, Fiber-optic fluorosensor for oxygen and carbon dioxide, Analytical Chemistry, 60(1988) 2028-30.

[91] C. Preininger, I. Klimant, O.S. Wolfbeis, Optical fiber sensor for biological oxygen demand, Analytical Chemistry, 66(1994) 1841-6.

[92] S. Satienperakul, T.J. Cardwell, R.W. Cattrall, I.D. McKelvie, D.M. Taylor, S.D. Kolev, Determination of carbon dioxide in gaseous samples by gas diffusion-flow injection, Talanta, 62(2004) 631-6.

[93] M.D. DeGrandpre, Measurement of seawater $\mathrm{pCO}_{2}$ using a renewable-reagent fiber optic sensor with colorimetric detection, Analytical Chemistry, 65(1993) 331-7.

[94] W. Frenzel, J. Schulz-Brüssel, B. Zinvirt, Characterisation of a gas-diffusion membrane-based optical flow-through sensor exemplified by the determination of nitrite, Talanta, 64(2004) 278-82.

[95] H. Mana, U. Spohn, Sensitive and selective flow injection analysis of hydrogen sulfite/sulfur dioxide by fluorescence detection with and without membrane separation by gas diffusion, Analytical Chemistry, 73(2001) 3187-92.

[96] K. Schmitt, J. Rist, C. Peter, J. Wöllenstein, Low-cost fiber-optic waveguide sensor for the colorimetric detection of ammonia, Microsystem Technologies, 18(2012) 843-8.

[97] S. Willason, K. Johnson, A rapid, highly sensitive technique for the determination of ammonia in seawater, Marine Biology, 91(1986) 285-90.

[98] G. Schulze, C.Y. Liu, M. Brodowski, O. Elsholz, W. Frenzel, J. Möller, Different approaches to the determination of ammonium ions at low levels by flow injection analysis, Analytica Chimica Acta, 214(1988) 121-36.

[99] D.G. Themelis, S.C. Karastogianni, P.D. Tzanavaras, Selective determination of cyanides by gas diffusion-stopped flow-sequential injection analysis and an on-line standard addition approach, Analytica Chimica Acta, 632(2009) 93-100.

[100] E. Bromage, T. Lackie, M. Unger, J. Ye, S. Kaattari, The development of a real-time biosensor for the detection of trace levels of trinitrotoluene (TNT) in aquatic environments, Biosensors and Bioelectronics, 22(2007) 2532-8.

[101] S.D. Soelberg, T. Chinowsky, G. Geiss, C.B. Spinelli, R. Stevens, S. Near, et al., A portable surface plasmon resonance sensor system for real-time monitoring of small to large analytes, Journal of Industrial Microbiology and Biotechnology, 32(2005) 669-74.

[102] K.R. Rogers, C.L. Gerlach, Peer reviewed: environmental biosensors: a status report, Environmental Science \& Technology, 30(1996) 486A-91A.

[103] M. Badihi-Mossberg, V. Buchner, J. Rishpon, Electrochemical biosensors for pollutants in the environment, Electroanalysis, 19(2007) 2015-28.

[104] S. Cosnier, C. Innocent, Y. Jouanneau, Amperometric detection of nitrate via a nitrate reductase immobilized and electrically wired at the electrode surface, Analytical Chemistry, 66(1994) 3198-201.

[105] Z. Liu, Y. Wang, S.P. Kounaves, E.J. Brush, Determination of organonitriles using enzymebased selectivity mechanisms. 1. An ammonia gas sensing electrode-based sensor for benzonitrile, Analytical Chemistry, 65(1993) 3134-6.

[106] P.A. Nader, S.S. Vives, H.A. Mottola, Studies with a sulfite oxidase-modified carbon paste electrode for detection/determination of sulfite ion and $\mathrm{SO}_{2}(\mathrm{~g})$ in continuous-flow systems, Journal of Electroanalytical Chemistry and Interfacial Electrochemistry, 284(1990) 323-33.

[107] J.-L. Weng, M.H. Ho, W.K. Nonidez, Amperometric determination of formaldehyde via the hexacyanoferrate (III)-coupled dehydrogenase reaction, Analytica Chimica Acta, 233(1990) 59-63. 
[108] J.P. Kim, B.Y. Lee, S. Hong, S.J. Sim, Ultrasensitive carbon nanotube-based biosensors using antibody-binding fragments, Analytical Biochemistry, 381(2008) 193-8.

[109] G. Cheol Gil, R.J. Mitchell, S. Tai Chang, M. Bock Gu, A biosensor for the detection of gas toxicity using a recombinant bioluminescent bacterium, Biosensors and Bioelectronics, 15(2000) 2330.

[110] S. Girotti, E.N. Ferri, M.G. Fumo, E. Maiolini, Monitoring of environmental pollutants by bioluminescent bacteria, Analytica Chimica Acta, 608(2008) 2-29.

[111] Y. Herschkovitz, I. Eshkenazi, C.E. Campbell, J. Rishpon, An electrochemical biosensor for formaldehyde, Journal of Electroanalytical Chemistry, 491(2000) 182-7.

[112] M. Hämmerle, S. Achmann, R. Moos, Gas Diffusion Electrodes for Use in an Amperometric Enzyme Biosensor, Electroanalysis, 20(2008) 2279-86.

[113] K. Mitsubayashi, K. Yokoyama, T. Takeuchi, I. Karube, Gas-Phase Biosensor for Ethanol, Analytical Chemistry, 66(1994) 3297-302.

[114] F. Arduini, A. Amine, D. Moscone, F. Ricci, G. Palleschi, Fast, sensitive and cost-effective detection of nerve agents in the gas phase using a portable instrument and an electrochemical biosensor, Analytical and Bioanalytical Chemistry, 388(2007) 1049-57.

[115] A. Kaisheva, I. Iliev, S. Christov, R. Kazareva, Electrochemical gas biosensor for phenol, Sensors and Actuators B: Chemical, 44(1997) 571-7.

[116] L. Rotariu, C. Bala, V. Magearu, New potentiometric microbial biosensor for ethanol determination in alcoholic beverages, Analytica Chimica Acta, 513(2004) 119-23.

[117] vel, T.K. Krawczyk, M. Trojanowicz, A. Lewenstam, Enzymatic flow-injection determination of urea in blood serum using potentiometric gas sensor with internal nonactin based ISE, Talanta, 41(1994) 1229-36.

[118] B.S. Walters, T.J. Nielsen, M.A. Arnold, Fiber-optic biosensor for ethanol, based on an internal enzyme concept, Talanta, 35(1988) 151-5.

[119] J.W. Aylott, D.J. Richardson, D.A. Russell, Optical biosensing of gaseous nitric oxide using spin-coated sol-gel thin films, Chemistry of Materials, 9(1997) 2261-3.

[120] S.H. Choi, M.B. Gu, A portable toxicity biosensor using freeze-dried recombinant bioluminescent bacteria, Biosensors and Bioelectronics, 17(2002) 433-40.

[121] F. Laganà, G. Barbieri, E. Drioli, Direct contact membrane distillation: modelling and concentration experiments, Journal of Membrane Science, 166(2000) 1-11.

[122] J. Phattaranawik, R. Jiraratananon, A. Fane, Heat transport and membrane distillation coefficients in direct contact membrane distillation, Journal of Membrane Science, 212(2003) 177-93. [123] R. Pasternak, M. Christensen, J. Heller, Diffusion and permeation of oxygen, nitrogen, carbon dioxide, and nitrogen dioxide through polytetrafluoroethylene, Macromolecules, 3(1970) 366-71.

[124] J.M. LaManna, S.G. Kandlikar, Determination of effective water vapour diffusion coefficient in pemfc gas diffusion layers, International Journal of Hydrogen Energy, 36(2011) 5021-9. 


\section{Figure Captions}

Figure 1 Schematic diagram of a typical membrane-based sensor for gas analytes.

Figure 2 (a) Schematic diagram of separation of gas mixture of species $\mathrm{i} \bigcirc$ and $\mathrm{j} \odot$, and important membrane diffusion parameters, including the permeability $\left(P_{M}\right)$, permeated flux $(J)$ and selectivity $\left(S_{i, j}\right)$ for species $i$ and $j$; (b) schematic diagram of gradient concentration distribution profiles of the species $i$ across the membrane.

Figure 3 Schematic diagrams of gas diffusion mechanisms (a) bulk poiseuille flow, (b) Knudsen diffusion, (c) size-restricted diffusion (left inset: surface model and right inset: gas-translational model), and (d) solid-state diffusion mechanism.

Figure 4 Schematic diagrams of three typical membrane-based electrochemical gas sensors (a) potentiometric sensor, (b) amperometric sensor, and (c) conductimetric sensor.

Figure 5 Schematic diagrams of membrane-based optical sensors.

Figure 6 Schematic diagrams of membrane-based biosensors (a) electrochemical biosensor and (b) optical biosensor.

Figure 7 (a) Schematic diagram of typical optical fibre ammonia gas sensor and probe response curve. (a, gas-permeable membrane; b, O-ring; c, internal electrolyte solution; d, epoxy; e, optical fibres; f, outer pipet tip; and g, inner pipet tip; A, internal electrolyte solution; B, gas-permeable membrane; C, sample solution) [88]. (b) Schematic diagram of general flow injection system and detector readout for a complete measurement cycle. (P1/P2, peristaltic pumps; $\mathrm{MC}$, mixing coil; $\mathrm{C} / \mathrm{S}$, carrier or sample solution; $\mathrm{R}_{1}$, releasing agent; $\mathrm{R}_{2}$, receiver solution; $\mathrm{D}$, flow-through sensor with detector; 1 , stop of the receiver flow; 2, re-start of the receiver flow; a, baseline before sample introduction; b, 
continuous decrease of transmission due to analyte concentration; c, decrease to baseline through washing the receiver solution out of the flow-through sensor) [94]. 